\title{
Serum Lipid and Adiponectin Improvements after a Mediterranean Dietary Pattern in Non-G-Allele Carriers of the Variant rs3774261
}

\author{
Daniel A. de Luis David Primo Olatz Izaola Emilia Gómez Rosario Bachiller \\ Institute of Endocrinology and Nutrition, Medicine School and Department of Endocrinology and Investigation, \\ Hospital Clinico Universitario, University of Valladolid, Valladolid, Spain
}

\section{Keywords}

Adiponectin · Lipid profile · Mediterranean diet · Singlenucleotide polymorphism

\begin{abstract}
Background: The role of adiponectin (ADIPOQ) polymorphisms in weight loss and serum lipid changes following different dietary interventions remain unclear. The Mediterranean dietary pattern has been associated with improved cardiovascular risk factors in different studies. Objective: Our aim was to analyze the effects of a hypocaloric diet with a Mediterranean dietary pattern on the metabolic response and adiposity parameters, taking into account the $712 \mathrm{G} / \mathrm{A}$ rs3774261 polymorphisms in ADIPOQ. Design: A population of 135 obese patients was enrolled. Anthropometric and serum parameters (lipid profile, insulin, homeostasis model assessment for insulin resistance [HOMA-IR], glucose, C-reactive protein [CRP], adiponectin, resistin, and leptin levels) were measured before and after the dietary intervention (12 weeks). All of the patients were genotyped for the rs3774261 polymorphism. Results: The genotype distribution of this population was 36 patients with AA (26.7\%), 68 patients with AG (50.4\%), and 31 patients with GG (22.9\%). After the dietary intervention and in both genotypes, BMI, weight, fat mass, systolic blood pressure, waist circumference, glucose,
\end{abstract}

karger@karger.com www.karger.com/lfg

Karger $\frac{1}{6}$

GOPEN ACCESS
(C) 2020 The Author(s)

Published by S. Karger AG, Basel

This article is licensed under the Creative Commons AttributionNonCommercial-NoDerivatives 4.0 International License (CC BYNC-ND) (http://www.karger.com/Services/OpenAccessLicense) Usage and distribution for commercial purposes as well as any distribution of modified material requires written permission. insulin, HOMA-IR, and leptin levels all decreased. After the dietary intervention with secondary weight loss and in nonG-allele carriers (AA vs. AG+GG), total cholesterol $(\Delta=-15.7$ \pm 3.9 vs. $-4.9 \pm 2.9 \mathrm{mg} / \mathrm{dL} ; p=0.02)$, LDL cholesterol $(\Delta=$ $-15.3 \pm 3.8$ vs. $-1.7 \pm 1.9 \mathrm{mg} / \mathrm{dL} ; p=0.01)$, triglyceride levels $(\Delta=-23.4 \pm 5.6$ vs. $2.3 \pm 2.3 \mathrm{mg} / \mathrm{dL} ; p=0.01)$, and $\operatorname{CRP}(\Delta=$ $-1.1 \pm 0.1$ vs. $-0.4 \pm 0.2 \mathrm{mg} / \mathrm{dL} ; p=0.01)$ decreased. Adiponectin levels ( $\Delta=7.2 \pm 2.1$ vs. $-0.4 \pm 0.3 \mathrm{ng} / \mathrm{dL} ; p=0.02)$ increased. Notably, G-allele carriers did not show this improvement. Conclusion: Non-G-allele carriers of the $A D I P O Q$ variant (rs3774261) showed significant improvement in serum levels of adiponectin, lipid profiles, and CRP in response to a hypocaloric diet with a Mediterranean dietary pattern.

(c) 2020 The Author(s)

Published by S. Karger AG, Basel

\section{Introduction}

Adiponectin is the most abundant protein secreted by adipose tissue [1]. Contrary to most adipokines, adiponectin levels are decreased in obese subjects and increased after weight reduction [2]. Some studies have demonstrated that adiponectin levels are associated with lipid and glucose metabolism [3, 4], Low adiponectin levels may increase the risk of obesity, diabetes mellitus, hyper- 
lipidemia, and insulin resistance [5]. Moreover, adiponectin is a potential target for therapeutic intervention in diabetes and obesity, with analogs or different strategies to increase its levels [6].

The serum levels of adiponectin are highly heritable and associated with different variants of the adiponectin $\mathrm{C} 1 \mathrm{Q}$ and the collagen domain containing (ADIPOQ) gene, which is located on chromosome 3q27. In some studies, ADIPOQ single-nucleotide polymorphisms (SNP) have been associated with obesity and diabetes mellitus [7]. One of these SNP, i.e., 712 G/A rs3774261 in $A D I P O Q$, has drawn much attention [7]. In particular, this SNP has been associated with cardiovascular events [8]; however, studies with on SNP are scarce and have been mainly conducted in Asian populations $[8,9]$. Despite the importance of this SNP in different comorbidities related to obesity and the potential improvement of these comorbidities with weight loss, we have not found a study in the literature assessing the role of this SNP during a nutritional intervention. This is a research area with interest, since weight reduction increases serum adiponectin levels [10] and this weight loss could be achieved with a Mediterranean dietary pattern, as indicated in a systematic review [11]. The benefits of a diet with a Mediterranean pattern may be due to weight loss but also to the presence of various nutrients such as monounsaturated fats, omega 3 fats, and fiber, all of which may improve adiponectin levels and cardiovascular risk markers independently of weight loss [11]. No specific studies to date have evaluated the interaction of SNP in the $A D I P O Q$ gene and the effect of a diet with a Mediterranean pattern. One of the few studies with a diet low in saturated fat and calorie restriction (but not a Mediterranean pattern) is the Finish Diabetes Prevention Study, which showed that another genetic variant in $A D I P O Q$ (rs266729) contributed to variations in body weight, serum adiponectin levels, and risk of diabetes mellitus type 2 [12]. Therefore, we felt that it was justified to evaluate the influence of a Mediterranean diet pattern on different parameters taking into account the rs3774261 in ADIPOQ.

Given the lack of studies in this area, and the fact that the Mediterranean dietary pattern has demonstrated multiple metabolic advantages, such as weight loss, lipid control, and glucose levels [13], in different studies, we designed a study to analyze the effects of a hypocaloric diet with a Mediterranean dietary pattern on metabolic response and adiposity parameters, taking into account the rs3774261 SNP in ADIPOQ.

rs3774261 of the ADIPOQ Gene and a Mediterranean Diet

\section{Subjects and Methods}

\section{Subjects and Clinical Investigation}

One hundred thirty-five obese Caucasian subjects participated in this study. The subjects were recruited from primary care physician practices in an urban area of Spain. The exclusion criteria were: a history of cardiovascular disease, thyroid disease, renal, or hepatic disorders; a history of alcoholism; malignant tumor; and, within the 6 months prior to this study, use of medications known to influence lipid levels (fibrates, statins, hormonal therapy, glucocorticoids, and anti-inflammatory drugs) or glucose levels (sulfonylureas, thiazolidinedione, insulin, glucagon-like peptide-1 [GLP-1] receptor antagonists, sodium glucose cotransporter 2 [SGLT2] inhibitors, dipeptidyl peptidase-4 [DPP4] inhibitors, or metformin).

Subjects taking any nutrient supplements were also excluded. All of the included patients fulfilled the following criteria: age between 25 and 75 years and an obesity diagnosis based on a BMI $\geq 30$.

Data was collected from all of the patients before and after the 12 weeks of dietary treatment. Data on anthropometric parameters (weight, height, BMI, waist circumference [WC], and fat mass by impedance) and blood pressure were recorded. Blood samples were collected in EDTA for analysis of insulin, total cholesterol, low-density lipoprotein (LDL) cholesterol, high-density lipoprotein (HDL) cholesterol, triglycerides, serum adipokine levels (leptin, total adiponectin, and resistin), C-reactive protein (CRP), and measured homeostasis model assessment for insulin resistance (HOMA-IR).

\section{Nutritional Treatment}

This study aimed to achieve a reduction of 500 daily calories compared to the usual intake. The subjects in this interventional study received individualized counseling on diet and exercise. At baseline, the normal dietary habits of subjects were assessed using 3 -day food records. The dietary intervention was a hypocaloric diet with a Mediterranean dietary pattern for 12 weeks. Food tables were used with a Mediterranean dietary pattern, including legumes, vegetables, poultry, whole grains, fish, fresh fruit, olive oil, and limited unhealthy fats such as margarines, fatty meats, snacks, and industrial pastries [14]. The percentage of kilocalories of macronutrients was: carbohydrates, $54 \%$; lipids, $25 \%$; and proteins, $21 \%$. The percentage of fats was: monounsaturated fats, $50.8 \%$; saturated fats, $37.3 \%$; and polyunsaturated fats, $11.9 \%$. All of the participants had 2 individual sessions $(60 \mathrm{~min}$ with diet sheets and example menu plans) with the dietitian at the start of the trail to explain the diet and resolve doubts. The dietitian assessed the adherence of this diet every 7 days with a phone call. All of the enrolled subjects received the instruction to record their daily dietary intake for 3 days, including a weekend day. Records were analyzed with a computer-based data evaluation system (Dietosource ${ }^{\circledR}$; GE). National composition food tables were used as a reference [14]. The exercise program consisted of aerobic exercise at least 3 times a week ( $60 \mathrm{~min}$ each) and the patient recorded it using a selfreported questionnaire.

\section{Genotyping the rs3774261 Variant}

The variant rs3774261 in ADIPOQ was determined by realtime polymerase chain reaction. Buffy coats removed from blood samples were stored in EDTA at $-20^{\circ} \mathrm{C}$. Genomic DNA was ex- 
Table 1. Anthropometric parameters and blood pressure according by genotype group

\begin{tabular}{|c|c|c|c|c|c|c|c|c|}
\hline \multirow[t]{2}{*}{ Parameter } & \multicolumn{2}{|l|}{$\mathrm{AA}(n=36)$} & \multicolumn{2}{|c|}{$\mathrm{AG}+\mathrm{GG}(n=99)$} & \multicolumn{4}{|l|}{$p$ values } \\
\hline & baseline & 3 months & baseline & 3 months & AA time ${ }^{a}$ & $\begin{array}{l}\text { baseline } \\
\text { genotype }^{b}\end{array}$ & $\begin{array}{l}\mathrm{AG}+\mathrm{GG} \\
\text { time }^{\mathrm{c}}\end{array}$ & $\begin{array}{l}\text { 12-week } \\
\text { geno- } \\
\text { type }^{\mathrm{d}}\end{array}$ \\
\hline BMI & $35.6 \pm 6.1$ & $34.1 \pm 6.2^{*}$ & $35.7 \pm 5.3$ & $34.2 \pm 4.9^{*}$ & 0.02 & 0.37 & 0.01 & 0.36 \\
\hline Weight, kg & $93.4 \pm 9.6$ & $90.1 \pm 9.1^{\$}$ & $95.0 \pm 9.1$ & $91.9 \pm 6.3^{\$}$ & 0.03 & 0.33 & 0.02 & 0.45 \\
\hline Fat mass, kg & $42.2 \pm 12.2$ & $39.4 \pm 9.1^{\#}$ & $40.7 \pm 8.1$ & $37.9 \pm 7.0^{\#}$ & 0.03 & 0.42 & 0.02 & 0.43 \\
\hline $\mathrm{WC}, \mathrm{cm}$ & $112.9 \pm 15.1$ & $109.3 \pm 8.1^{\&}$ & $109.9 \pm 6.9$ & $104.9 \pm 8.1^{\&}$ & 0.03 & 0.51 & 0.02 & 0.48 \\
\hline $\mathrm{SBP}, \mathrm{mm} \mathrm{Hg}$ & $130.6 \pm 9.2$ & $120.0 \pm 4.9^{* *}$ & $130.1 \pm 7.1$ & $123.6 \pm 6.2^{* *}$ & 0.03 & 0.37 & 0.04 & 0.41 \\
\hline $\mathrm{DBP}, \mathrm{mm} \mathrm{Hg}$ & $81.8 \pm 7.1$ & $80.4 \pm 4.1$ & $79.9 \pm 6.0$ & $80.9 \pm 7.0$ & 0.51 & 0.62 & 0.63 & 0.55 \\
\hline
\end{tabular}

Values are presented as means \pm SD. DBP, diastolic blood pressure; SBP, systolic blood pressure. $p<0.05$ for each genotype group (* BMI, ${ }^{\$}$ weight, ${ }^{\#}$ fat mass, ${ }^{\&} \mathrm{WC}$, and ${ }^{* *}$ SBP $) .{ }^{\text {a }}$ Significance of the dietary intervention after 12 weeks in the AA genotype. ${ }^{\mathrm{b}}$ Significance between AA genotypes vs. AG+GG baseline values. ${ }^{c}$ Significance of the dietary intervention after 12 weeks in the AG+GG genotype. d Significance between AA genotypes vs. AG+GG posttreatment values.

Table 2. Biochemical parameters in genotype groups

\begin{tabular}{|c|c|c|c|c|c|c|c|c|}
\hline \multirow[t]{2}{*}{ Parameter } & \multicolumn{2}{|l|}{$\mathrm{AA}(n=36)$} & \multicolumn{2}{|c|}{$\mathrm{AG}+\mathrm{GG}(n=99)$} & \multicolumn{4}{|l|}{$p$ value } \\
\hline & baseline & 3 months & baseline & 3 months & AA time & $\begin{array}{l}\text { baseline } \\
\text { genotype }^{b}\end{array}$ & $\begin{array}{l}\mathrm{AG}+\mathrm{GG} \\
\text { time }^{\mathrm{c}}\end{array}$ & $\begin{array}{l}\text { 12-week } \\
\text { genotype }^{\mathrm{d}}\end{array}$ \\
\hline Glucose, mg/dL & $100.8 \pm 9.1$ & $95.7 \pm 7.0^{*}$ & $99.9 \pm 8.0$ & $95.9 \pm 7.1^{*}$ & 0.01 & 0.56 & 0.02 & 0.43 \\
\hline Total cholesterol, mg/dL & $208.9 \pm 12.7$ & $192.2 \pm 11.2^{\$}$ & $199.2 \pm 8.1$ & $194.4 \pm 10.2$ & 0.03 & 0.51 & 0.12 & 0.34 \\
\hline LDL cholesterol, mg/dL & $129.9 \pm 10.3$ & $114.3 \pm 8.9^{\#}$ & $118.5 \pm 5.1$ & $116.8 \pm 9.1$ & 0.01 & 0.49 & 0.35 & 0.34 \\
\hline HDL cholesterol, mg/dL & $54.4 \pm 4.1$ & $55.2 \pm 5.1$ & $50.9 \pm 5.0$ & $49.7 \pm 5.1$ & 0.21 & 0.47 & 0.59 & 0.45 \\
\hline Triglycerides, mg/dL & $148.2 \pm 17.1$ & $124.8 \pm 11.2^{+}$ & $121.1 \pm 12.2$ & $117.8 \pm 11.2$ & 0.02 & 0.61 & 0.21 & 0.45 \\
\hline Insulin, mUI/L & $19.9 \pm 7.1$ & $15.6 \pm 5.1^{\&}$ & $17.6 \pm 6.2$ & $13.5 \pm 6.0^{\&}$ & 0.02 & 0.39 & 0.03 & 0.41 \\
\hline HOMA-IR & $5.2 \pm 2.1$ & $3.7 \pm 1.8^{* *}$ & $4.9 \pm 2.1$ & $3.1 \pm 2.1^{* *}$ & 0.01 & 0.36 & 0.02 & 0.43 \\
\hline CRP & $7.4 \pm 2.1$ & $6.3 \pm 1.2^{\& \&}$ & $4.6 \pm 2.1$ & $4.2 \pm 2.2$ & 0.01 & 0.36 & 0.37 & 0.43 \\
\hline
\end{tabular}

Values are presented as means \pm SD. $p<0.05$ for each genotype group $\left({ }^{*}\right.$ glucose, ${ }^{\$}$ total cholesterol, ${ }^{*}$ LDL cholesterol, ${ }^{+}$triglycerides, \& insulin, ${ }^{* *}$ HOMA IR, and ${ }^{\& \&}$ CRP). a Significance of the dietary intervention after 12 weeks in the AA genotype. ${ }^{\text {b }}$ Significance between AA genotypes vs. AG + GG baseline values. ${ }^{c}$ Significance of the dietary intervention after 12 weeks in the AG + GG genotype. d Significance between AA genotypes vs. AG + GG posttreatment values.

tracted from $150 \mu \mathrm{L}$ buffy coat using a blood genomic kit (Bio$\operatorname{Rad}^{\circledR}$, Hercules, CA, USA) according to the manufacturer's instructions. Oligonucleotide primers and probes were performed with a Beacon Designer 5.0 device (Premier Biosoft Internation$\mathrm{al}^{\circledR}$, Los Angeles, CA, USA). The polymerase chain reaction (PCR) was carried out with $50 \mathrm{ng}$ of this genomic DNA, $0.5 \mu \mathrm{L}$ of each oligonucleotide primer (primer forward: $5^{\prime}$-ACGTTGGATGCTCCTCCTTGAAGCCTTCAT- $3^{\prime}$ and reverse $5^{\prime}$-ACGTTGGATGCAAGTATTCAAAGTATGGAGC- $3^{\prime}$ ) in a final volume of $2 \mu \mathrm{L}$ (Termocicler Life Technologies, Los Angeles, CA, USA). DNA was denaturated at $90^{\circ} \mathrm{C}$ for $3 \mathrm{~min}$; this was followed by 50 cycles of denaturation at $90^{\circ} \mathrm{C}$ for $20 \mathrm{~s}$ and annealing at $58.1^{\circ} \mathrm{C}$ for $45 \mathrm{~s}$. The PCR were run in a $25-\mu \mathrm{L}$ final volume containing $10.5 \mu \mathrm{L}$

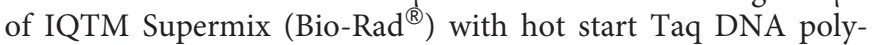
merase.

\section{Measurements}

The method used for measurement of glucose levels was an automated glucose oxidase method (Glucose Analyzer 2; Beckman Instruments, Fullerton, CA, USA). Insulin was determined by RIA (RIA Diagnostic Corporation, Los Angeles, CA, USA) with a sensitivity of $0.5 \mathrm{mUI} / \mathrm{L}$ (normal range $0.5-30 \mathrm{mUI} / \mathrm{L}$ ) [15]. The HOMA-IR was calculated based on glucose and insulin values using the following formula: glucose $(\mathrm{mg} / \mathrm{dL}) \times$ insulin $(\mathrm{UI} / \mathrm{L}) / 22.5$ [16].

Enzymatic colorimetric assay (Technicon Instruments, Ltd., New York, NY, USA) was used to measure total cholesterol and triglycerides, while HDL cholesterol was analyzed enzymatically in the supernatant after precipitation of other lipoproteins with dextran sulfate-magnesium, and finally LDL cholesterol was calculated using the Friedewald formula [17]. 
Table 3. Serum adipokine levels in the genotype groups

\begin{tabular}{|c|c|c|c|c|c|c|c|c|}
\hline \multirow[t]{2}{*}{ Parameters } & \multicolumn{2}{|c|}{$\mathrm{AA}(n=36)$} & \multicolumn{2}{|c|}{$\mathrm{AG}+\mathrm{GG}(n=99)$} & \multicolumn{4}{|l|}{$p$ values } \\
\hline & baseline & 3 months & baseline & 3 months & AA time ${ }^{\mathrm{a}}$ & $\begin{array}{l}\text { baseline } \\
\text { genotype }^{\text {b }}\end{array}$ & $\begin{array}{l}\text { AG+GG } \\
\text { time }^{c}\end{array}$ & $\begin{array}{l}\text { 12-week } \\
\text { genotype }^{\mathrm{d}}\end{array}$ \\
\hline Resistin, ng/dL & $3.8 \pm 1.9$ & $3.7 \pm 3.0$ & $4.0 \pm 2.1$ & $3.9 \pm 1.9$ & 0.52 & 0.61 & 0.14 & 0.45 \\
\hline Adiponectin, ng/dL & $17.7 \pm 5.1$ & $24.9 \pm 4.0^{\$}$ & $18.8 \pm 5.1$ & $18.3 \pm 4.2$ & 0.02 & 0.81 & 0.22 & 0.76 \\
\hline Leptin, ng/dL & $94.3 \pm 12.6$ & $81.1 \pm 9.5^{*}$ & $79.2 \pm 13.1$ & $67.8 \pm 9.1^{*}$ & 0.02 & 0.22 & 0.03 & 0.33 \\
\hline
\end{tabular}

Values are presented as means \pm SD. $p<0.05$ for each genotype group (* leptin and ${ }^{\$}$ adiponectin). ${ }^{\text {a }}$ Significance of the dietary intervention after 12 weeks in the AA genotype. ${ }^{b}$ Significance between AA genotypes vs. AG+GG baseline values. ${ }^{c}$ Significance of the dietary intervention after 12 weeks in the AG + GG genotype. ${ }^{\mathrm{d}}$ Significance between AA genotypes vs. AG+GG post-treatment values.

Serum adiponectin levels were analyzed by ELISA (R\&D Systems, Inc., USA), with a sensitivity of $0.246 \mathrm{ng} / \mathrm{mL}$ and a normal range of $8.65-21.43 \mathrm{ng} / \mathrm{mL}[18]$. Resistin levels were analyzed by ELISA (Biovendor Laboratory, Inc., Brno, Czech Republic) with a sensitivity of $0.2 \mathrm{ng} / \mathrm{mL}$ and a normal range of $4-12 \mathrm{ng} / \mathrm{mL}$ [19]. Leptin levels was measured by ELISA (Diagnostic Systems Laboratories, Inc., USA) with a sensitivity of $0.05 \mathrm{ng} / \mathrm{mL}$ and a normal range of $10-100 \mathrm{ng} / \mathrm{mL}$ [20]. CRP was measured by immunoturbimetry (Roche Diagnostics $\mathrm{GmbH}$, Mannheim, Germany) with a normal range of $0-7 \mathrm{mg} / \mathrm{dL}$ and analytical sensitivity of $0.5 \mathrm{mg} / \mathrm{dL}$.

\section{Anthropometric Parameters}

In order to calculate the BMI, height and weight were measured using a telescopic height-measuring instrument (Omrom, Los Angeles, CA, USA) and an electrical scale (Omrom), respectively. BMI was calculated as body weight $(\mathrm{kg})$ divided by height $(\mathrm{m})$ squared. WC was determined with a flexible nonstretchable measuring tape (Type SECA; SECA, Birmingham, UK). Bio impedance was used to determine the body composition with an accuracy of $5 \mathrm{~g}$ [21] (EFG; Akern). Blood pressure was measured 3 times at 10min intervals using a mercury sphygmomanometer (Omrom) and averaged.

\section{Statistical Analysis}

The sample size was calculated to detect differences over $2.5 \mathrm{~kg}$ in body weight loss, with $90 \%$ power and $5 \%$ significance $(n=80)$. The Kolmogorov-Smirnov test was used to analyze the variable distribution. The results are reported as means \pm SD. Numerical variables with a normal distribution were analyzed using a twotailed Student $t$ test. Nonparametric variables were analyzed using the Mann-Whitney U test. Categorical variables were analyzed using the $\chi^{2}$ test, with Yates correction as necessary, and Fisher's test. The Bonferroni test was applied for multiple testing to reduce type I error in the association analysis. The statistical analysis to evaluate the interaction between the gene and the dietary intervention was performed using ANCOVA (covariance analysis) adjusted by age, sex, and BMI, modeling the dependent variable with the starting values. The $p$ values in Tables $1-3$ are as follows: the first $p$ corresponds to the significance of a dietary intervention after 12 weeks in the AA genotype, the second $p$ corresponds to the significance between AA genotypes vs. AG + GG baseline values, the third $p$ corresponds to the significance of a dietary intervention after 12 weeks in the AG + GG genotype, and the fourth $p$ corresponds to the significance between AA genotypes vs. AG + GG posttreatment values. Hardy-Weinberg equilibrium was assessed with a statistical test $\left(\chi^{2}\right)$ to compare our expected and observed data. Hardy-Weinberg equilibrium in genotype frequencies was confirmed $(p=0.28)$. All analyses were performed under a dominant genetic model with the rs3774261 G allele as the risk allele (AG + GG vs. AA). All of the data were analyzed using SPSS for Windows, version 23.0 (SPSS Inc., Chicago, IL, USA). $p<0.05$ was considered statistically significant.

\section{Results}

We evaluated the effects of the rs3774261 SNP on the change in anthropometric and biochemical parameters in 135 obese subjects following a dietary intervention with a Mediterranean pattern. The evaluation was done in a dominant model, i.e., AG + GG vs. AA, and the presence of $1 \mathrm{G}$ allele was considered as a risk allele. The mean age of the entire population was $48.1 \pm 5.0$ years (range 25 63 ) and the average BMI was 35.6 \pm 5.9 (range 31.4-39.8). The gender distribution was 94 females $(69.6 \%)$ and 41 males $(30.4 \%)$. The genotype distribution of this population was 36 patients with AA (26.7\%), 68 patients with AG (50.4\%), and 31 patients with GG (22.9\%). The variant was in Hardy-Weinberg equilibrium $(p=0.28)$. Epidemiological data were similar across all genotype groups. The gender distribution was similar across the genotype groups (AA: $26.0 \%$ males vs. $74.0 \%$ females; AG: $32.4 \%$ males vs. $67.6 \%$ females; and GG: $32.3 \%$ males vs. $67.7 \%$ females). The distribution of sex with the dominant model was similar (AA: $27.7 \%$ males and $62.3 \%$ females vs. AG+GG: $32.3 \%$ males and $66.7 \%$ females; ns), too. Age values were similar in these groups (AA: $48.3 \pm 5.1$ vs. AG: $49.9 \pm 5.2$ vs. GG: $47.9 \pm 4.9$ years; ns). Age values were similar in the dominant model (AA: $48.3 \pm 5.1 \mathrm{vs.} \mathrm{AG+GG:}$ $48.1 \pm 3.2$ years; $n s)$, too. 
Patients reached the dietary recommendations as indicated in Subjects and Methods, with a total caloric intake of $1,456.1 \pm 132.2 \mathrm{kcal}$. The percentage of kilocalories for the macronutrients was: carbohydrates, $53.3 \%$; lipids, $25.4 \%$, and proteins, $20.6 \%$. The percentage of fats was: monounsaturated fats, $52.1 \%$; saturated fats, $36.9 \%$; and polyunsaturated fats, $12.0 \%$, with no statistical differences between genotype groups. Basal physical activity values were similar in both genotype groups (AA vs. AG+GG: $113.2 \pm 21.3$ vs. $121.1 \pm 22.2 \mathrm{~min} /$ week; $p=0.50$ ). After the intervention, physical activity was similar to that at baseline, without differences in $\Delta(108.2 \pm 11.9$ vs. 106.1 $\pm 21.2 \mathrm{~min} /$ week; $p=0.3$ ).

\section{Anthropometric Results}

For rs3774261, there were no differences in anthropometric parameters or blood pressure with the dominant model (AA vs. AG+GG; Table 1). After the hypocaloric diet with a Mediterranean dietary pattern in both genotypes (AA vs. AG+GG), BMI $(\Delta:-1.5 \pm 0.3$ vs. $-1.3 \pm 0.2$ $\left.\mathrm{kg} / \mathrm{m}^{2} ; p=0.18\right)$, weight $(\Delta:-3.3 \pm 2.1$ vs. $-3.2 \pm 2.0 \mathrm{~kg}$; $p=0.21)$, fat mass $(\Delta:-2.8 \pm 1.2$ vs. $-2.9 \pm 1.0 \mathrm{~kg} ; p=0.33)$, WC $(\Delta:-3.7 \pm 1.1$ vs. $-5.0 \pm 1.3 \mathrm{~cm} ; p=0.40)$, and systolic blood pressure $(\Delta:-10.6 \pm 2.4$ vs. $-7.1 \pm 1.9 \mathrm{~mm} \mathrm{Hg}$; $p=0.32$ ) showed a statistical decrease in both genotype groups. The improvements were similar in both genotype groups.

\section{Biochemical Results}

Next, we investigated the effects of the dietary intervention on biochemical parameters, lipid profiles (Table 2 ), and adipokine levels (Table 3). After weight loss secondary to the diet intervention (AA vs. $A G+G G$ ), glucose $(\Delta:-5.1 \pm 1.4$ vs. $-4.0 \pm 1.3 \mathrm{mg} / \mathrm{dL} ; p=0.42)$, insulin levels $(\Delta:-4.3 \pm 0.9$ vs. $-4.1 \pm 0.8 \mathrm{UI} / \mathrm{L} ; p=0.33)$, and $\operatorname{HOMA}-\mathrm{IR}(\Delta:-1.5 \pm 0.2$ vs. $-1.8 \pm 0.5$ units; $p=0.41)$ improved in both genotype groups. After the dietary intervention (AA vs. AG+GG), total cholesterol $(\Delta:-15.7 \pm$ 3.9 vs. $-4.9 \pm 2.9 \mathrm{mg} / \mathrm{dL} ; p=0.02)$, LDL cholesterol $(\Delta$ : $-15.3 \pm 3.8$ vs. $-1.7 \pm 1.9 \mathrm{mg} / \mathrm{dL} ; p=0.01)$, triglyceride levels $(\Delta:-23.4 \pm 5.6$ vs. $2.3 \pm 2.3 \mathrm{mg} / \mathrm{dL} ; p=0.01)$, and $\mathrm{CRP}(\Delta:-1.1 \pm 0.1$ vs. $-0.4 \pm 0.2 \mathrm{mg} / \mathrm{dL} ; p=0.01)$ values improved in non-G-allele carriers. $\Delta$ represents the difference between baseline and postdiet time points, and it is significant only in patients with AA genotype.

\section{Adipokine Results}

Table 3 shows changes in serum adipokines. After weight loss and in AA carriers, serum adiponectin $(\Delta$ : AA: $7.2 \pm 2.1$ vs. $A G+\mathrm{GG}:-0.4 \pm 0.3 \mathrm{ng} / \mathrm{dL} ; p=0.02)$ increased. Only $\Delta$ was significant in non-G-allele carriers. In addition, patients with both genotypes showed a significant decrease in leptin levels $(\Delta:-13.2 \pm 4.1$ vs. -12.4 $\pm 3.9 \mathrm{ng} / \mathrm{dL} ; p=0.18$ ). Serum resistin levels remained unchanged during the intervention trial in both genotype groups.

\section{Discussion}

This study presents the first evidence that the ADIPOQ variant (rs3774261) is involved in the metabolic response secondary to a hypocaloric diet with a Mediterranean dietary pattern among obese subjects. Non-Gallele carriers (i.e., AA carriers) showed a better response in the levels of LDL cholesterol, triglycerides, CRP. and adiponectin compared to G-allele carriers (i.e., AG + GG). These metabolic results were observed with the same amount of weight loss.

There are some studies evaluating the association between this genetic variant (rs3774261) on ADIPOQ and diabetes mellitus, obesity, and serum adiponectin levels [22]. For example, Ramya et al. [23] reported that adiponectin gene variants and haplotype contributed to the genetic risk towards the development of type 2 diabetes, obesity, and hypoadiponectinemia in a south Indian population [23]. Moreover, there is a lack of information about the influence of dietary treatment on these metabolic relationships in interventional designs. Our study shows that this genetic variant in $A D I P O Q$ is associated with differential regulation of adiponectin synthesis after weight loss and this relationship could contribute to our findings related with lipid profile and CRP changes.

Wassel et al. [22] demonstrated that rs3774261 in ADIPOQ are strongly associated with serum adiponectin levels in Caucasian subjects. This genetic variant lies in an intronic region of the gene; however, there is evidence that introns of the protein-coding gene transcripts can modulate gene expression by repressing translation RNA transcripts [24]. In this case, rs3774261 is an intronic enhancer, and it could affect protein levels by altering transcription. The association of this genetic variant with adiponectin levels is independent of the BMI of the patients [9], and it seems to be related to ethnicity since it has only been found in European populations. However, no association has been reported in African Americans [25].

In some studies, this SNP has been related to the risk of coronary heart disease [26]. Kanu et al. [26] reported that the G allele of rs3774261 was significantly higher in coronary heart disease patients than in controls; however, 
the exact mechanism of this association was not well explained because no metabolic parameters were measured. A possible hypothesis is the anti-inflammatory and antiatherosclerotic effect of adiponectin. Moreover, epidemiological studies without evaluation of biochemical parameters have reported unclear effects of $A D I P O Q$ gene SNP, depending on the locus of polymorphisms studied [26]. Another study with 637 ischemic stroke patients [27] demonstrated that polymorphisms in ADIPOQ were associated with the risk of ischemic stroke in a Korean population and that the role of inflammation may be important.

Other types of epidemiological studies [28] have demonstrated the relationship of the $G$ allele with an increment in the risk of diabetes mellitus type 2. In addition, this relationship seems not to be due to the relationship with the insulin resistance of this polymorphism, as in our nutritional intervention study. As we have previously reported, ethnicity could influence the results, and in this way Specchia et al. [29] tested in African Americans how patients carrying the A allele have a greater insulin sensitivity as demonstrated by the euglycemic clamp.

There is a lack of nutritional intervention studies in the literature assessing the role of the rs3774261 SNP on weight loss or metabolic changes. However, there are studies that have evaluated the effect of other polymorphisms in the ADIPOQ in this topic area. For example, in a recent analysis of the Finnish Diabetes Prevention Program [11], a randomized, controlled multicenter study with a dietary intervention, the authors showed that the G allele in the rs266729 SNP was associated with higher weight after a 4-year follow-up and that the $\mathrm{C}$ allele was associated with an increased risk of developing type 2 diabetes mellitus. Our study did not show an effect of rs3774261 on weight loss, but we did find an effect on the modification of the lipid profile. Another interventional study with this SNP rs266729 was conducted in patients after bariatric surgery (Roux Y gastroenterostomy) [30]. Individuals with the $\mathrm{C}$ allele were more prone to showing a reduction of LDL cholesterol levels after bariatric surgery (i.e., -43 vs. $-18 \%$ ) compared to G-allele carriers.

A recent investigation described that the rs3774261 variant is related to a disinhibition of eating behaviors [31], influencing food uptake and energy expenditure in the arcuate hypothalamus. Minor allele carriers showed increased disinhibition scores, which indicates a tendency to overheat. Our present interventional study showed that AA carriers showed a better response of the levels of LDL cholesterol, triglycerides, CRP, and adiponectin compared to G-allele carriers. The exact mechanism to explain this association is not well understood. The beneficial metabolic effects obtained in our study on the levels of LDL cholesterol, triglycerides, and CRP may be related to a better response of adiponectin levels in patients carrying the G allele. Specifically, adiponectin, through regulation of lipoprotein lipase, can increase triglyceride hydrolysis with a high rate of catabolism. In addition, the association of circulating adiponectin with hepatic lipase activity could explain the relation to LDL cholesterol levels, too [32]. In the literature, adiponectin levels have been related to CRP levels, and it is in accordance with the anti-inflammatory effects of adiponectin in protecting against atherosclerosis [33]. On the other hand, the observed beneficial effects may be related not only to weight loss itself but also to the profile of the Mediterranean diet. The presence of nutrients such as olive oil, fish, and lean meats could also explain the improvement in the profile of lipid and inflammatory markers [11]. For example, the well-known anti-inflammatory effects of omega-3 fats, the lipid-lowering effects of omega- 9 fats, and the hyperlipemic effects of saturated fats from nonlean meats are aspects to consider with regard to the effect of this diet.

There are several important strengths of this study as an interventional trial, but there are also some limitations. First, we only analyzed 1 SNP of $A D I P O Q$, so other genetic variants could be related to metabolic parameters. Second, many uncontrolled factors (e.g., epigenetic factors, hormonal status, etc.) could have influences our results and this should be considered in future studies. Third, the lack of a control group without a diet might create a bias. Finally, the self-reported dietary intake is not reliable and might include the bias of under- or overreporting by patients. The strength of our study was in its design as an interventional controlled trial.

\section{Conclusion}

Non-G-allele carriers of the ADIPOQ variant (rs3774261) showed a significant improvement of serum levels of adiponectin, lipid profile, and CRP in response to a hypocaloric diet with a Mediterranean dietary pattern. Furthermore, G-allele carriers did not show these improvements. Moving forward, it is perhaps necessary to employ a more personalized approach in obese patients that takes into account our results. It may be necessary to have not only weight loss goals and an adequate dietary pattern but also the genotype of patients to better predict the benefits, or the absence thereof, of a response to a dietary intervention. 


\section{Statement of Ethics}

All of the procedures performed in studies involving human participants were in accordance with the ethical standards of the institutional and/or the national research committee and the 1964 Helsinki Declaration and its later amendments or comparable ethical standards. This study was approved by our local committee (Hospital Clinic Universitary of Valladolid Committee: PI7/2017). All of the participants provided written informed consent.

\section{Conflict of Interest Statement}

All of the authors declare that they have no conflict of interests.

\section{Funding Source}

There are no funding sources to declare.

\section{Author Contribution}

D.A.L. designed this study, conducted the statistical analysis, and contributed to the analysis of data for this work. O.I., E.G., and R.B. did the anthropometric evaluation, controlled the dietary intake, and contributed to the acquisition of data for this work. D.P. conducted the biochemical evaluation and genotyping and contributed to the analysis of data for this work. All of the authors revised this study critically for important intellectual content, approved the version to be published, and are accountable for all aspects of this work in ensuring that questions related to the accuracy or integrity of any part of this work are appropriately investigated and resolved.

\section{References}

1 Weyer C, Funahashi T, Tanaka S, Hotta K, Matsuzawa Y, Pratley RE, et al. Hypoadiponectinemia in obesity and type 2 diabetes: close association with insulin resistance and hyperinsulinemia. J Clin Endocrinol Metab. 2001 May;86(5):1930-5.

2 Ouchi N, Kihara S, Arita Y, Maeda K, Kuriyama $\mathrm{H}$, Okamoto $\mathrm{Y}$, et al. Novel modulator for endothelial adhesion molecules: adipocyte-derived plasma protein adiponectin. Circulation. 1999 Dec;100(25):2473-6.

3 Yang WS, Chuang LM. Human genetics of adiponectin in the metabolic syndrome. J Mol Med (Berl). 2006 Feb;84(2):112-21.

4 Takahashi M, Arita Y, Yamagata K, Matsukawa Y, Okutomi K, Horie M, et al. Genomic structure and mutations in adipose-specific gene, adiponectin. Int J Obes Relat Metab Disord. 2000 Jul;24(7):861-8.

5 Yamamoto Y, Hirose H, Saito I, Nishikai K, Saruta T. Adiponectin, an adipocyte-derived protein, predicts future insulin resistance: two-year follow-up study in Japanese population. J Clin Endocrinol Metab. 2004 Jan;89(1): 87-90.

6 Berg AH, Scherer PE. Adipose tissue, inflammation, and cardiovascular disease. Circ Res. 2005 May;96(9):939-49.

7 de Luis DA, Izaola O, de la Fuente B, Primo D, Fernández Ovalle H, Romero E. rs1501299 Polymorphism in the Adiponectin Gene and Their Association with Total Adiponectin Levels, Insulin Resistance and Metabolic Syndrome in Obese Subjects. Ann Nutr Metab. 2016;69(3-4):226-31.

8 Kanu JS, Gu Y, Zhi S, Yu M, Lu Y, Cong Y, et al. Single nucleotide polymorphism rs3774261 in the AdipoQ gene is associated with the risk of coronary heart disease (CHD) in Northeast Han Chinese population: a case-control study. Lipids Health Dis. 2016 Jan;15:6.
9 Apalasamy YD, Rampal S, Salim A, Moy FM, Bulgiba A, Mohamed Z. Association of ADIPOQ gene with obesity and adiponectin levels in Malaysian Malays. Mol Biol Rep. 2014 May; 41(5):2917-21.

10 Yang WS, Lee WJ, Funahashi T, Tanaka S, Matsuzawa Y, Chao CL, et al. Weight reduction increases plasma levels of an adipose-derived anti-inflammatory protein, adiponectin. J Clin Endocrinol Metab. 2001 Aug;86(8): 3815-9.

11 Mancini JG, Filion KB, Atallah R, Eisenberg MJ. Systematic Review of the Mediterranean Diet for Long-Term Weight Loss. Am J Med. 2016 Apr;129(4):407-15.e4.

12 Siitonen N, Pulkkinen L, Lindström J, Kolehmainen M, Eriksson JG, Venojärvi $M$, et al. Association of ADIPOQ gene variants with body weight, type 2 diabetes and serum adiponectin concentrations: the Finnish Diabetes Prevention Study. BMC Med Genet. 2011 Jan;12(1):5.

13 Widmer RJ, Flammer AJ, Lerman LO, Lerman A. The Mediterranean diet, its components, and cardiovascular disease. Am J Med. 2015 Mar; 128(3):229-38.

14 Mataix J, Mañas M. Tablas de composición de alimentos españoles. Granada: University of Granada; 2003.

15 Duart Duart MJ, Arroyo CO, Moreno Frígols $\mathrm{JL}$. Validation of a kinetic model for the reactions in RIA. Clin Chem Lab Med. 2002 Nov; 40(11):1161-7.

16 Matthews DR, Hosker JP, Rudenski AS, Naylor BA, Treacher DF, Turner RC. Homeostasis model assessment: insulin resistance and beta-cell function from fasting plasma glucose and insulin concentrations in man. Diabetologia. 1985 Jul;28(7):412-9.
17 Friedewald WT, Levy RI, Fredrickson DS. Estimation of the concentration of low-density lipoprotein cholesterol in plasma, without use of the preparative ultracentrifuge. Clin Chem. 1972 Jun;18(6):499-502.

18 Suominen P. Evaluation of an enzyme immunometric assay to measure serum adiponectin concentrations. Clin Chem. 2004 Jan;50(1): 219-21.

19 Pfützner A, Langenfeld M, Kunt T, Löbig M, Forst T. Evaluation of human resistin assays with serum from patients with type 2 diabetes and different degrees of insulin resistance. Clin Lab. 2003;49(11-12):571-6.

20 Khan SS, Smith MS. reda D, Suffredini AF, Mc Coy JP. Multiplex bead array assays for detection of soluble cytokines: comparisons of sensitivity and quantitative values among kits from multiple manufactures. Cytometry B Clin Cytom. 2004;61:35-9.

21 Lukaski HC, Johnson PE, Bolonchuk WW, Lykken GI. Assessment of fat-free mass using bioelectrical impedance measurements of the human body. Am J Clin Nutr. 1985 Apr;41(4): $810-7$.

22 Wassel CL, Pankow JS, Jacobs DR Jr, Steffes MW, Li N, Schreiner PJ. Variants in the adiponectin gene and serum adiponectin: the Coronary Artery Development in Young Adults (CARDIA) Study. Obesity (Silver Spring). 2010 Dec;18(12):2333-8.

23 Ramya K, Ashok Ayyappa K, Ghosh S, Mohan V. Radha Genetic Association of ADIPOQ Gene Variants With Type 2 Diabetes. Obesity and Serum Adiponectin Levels in South Indian Population. Gene. 2013;32:253-62.

24 Deng JH, Deng P, Lin SL, Ying SY. Gene silencing in vitro and in vivo using intronic microRNAs. Methods Mol Biol. 2015;1218:32140. 
25 Ling H, Waterworth DM, Stirnadel HA, Pollin TI, Barter PJ, Kesäniemi YA, et al. Genome-wide linkage and association analyses to identify genes influencing adiponectin levels: the GEMS Study. Obesity (Silver Spring). 2009 Apr;17(4):737-44.

26 Kanu JS, Gu Y, Zhi S, Yu M, Lu Y, Cong Y, et al. Single nucleotide polymorphism rs3774261 in the AdipoQ gene is associated with the risk of coronary heart disease (CHD) in Northeast Han Chinese population: a case-control study. Lipids Health Dis. 2016 Jan;15(1):6.

27 Cheong MY, Bang OS, Cha MH, Park YK, Kim SH, Kim YJ. Association of the adiponectin gene variations with risk of ischemic stroke in a Korean population. Yonsei Med J. 2011 Jan;52(1):20-5.

28 Yao M, Wu Y, Fang Q, Sun L, Li T, Qiao H. Association of ADIPOQ variants with type 2 diabetes mellitus susceptibility in ethnic Han Chinese from northeast China. J Diabetes Investig. 2016 Nov;7(6):853-9.

29 Specchia C, Scott K, Fortina P, Devoto M, Falkner B. Association of a polymorphic variant of the adiponectin gene with insulin resistance in african americans. Clin Transl Sci. 2008 Dec;1(3):194-9.

30 Gasparotto AS, Borges DO, Zandoná MR, Ramos MJ, Meihnardt NG, Mattevi VS. Adiponectin promoter polymorphisms are predic- tors of lipid profile improvement after bariatric surgery. Genet Mol Biol. 2017 Oct-Dec; 40(4):736-42.

31 Rohde K, Keller M, Horstmann A, Liu X, Eichelmann F, Stumvoll M, et al. Role of genetic variants in ADIPOQ in human eating behavior. Genes Nutr. 2015 Jan;10(1):449.

32 Christou GA, Kiortsis DN. Adiponectin and lipoprotein metabolism. Obes Rev. 2013 Dec; 14(12):939-49.

33 Matsushita K, Yatsuya H, Tamakoshi K, Wada K, Otsuka R, Zhang H, et al. Inverse association between adiponectin and C-reactive protein in substantially healthy Japanese men. Atherosclerosis. 2006 Sep;188(1):184-9. 